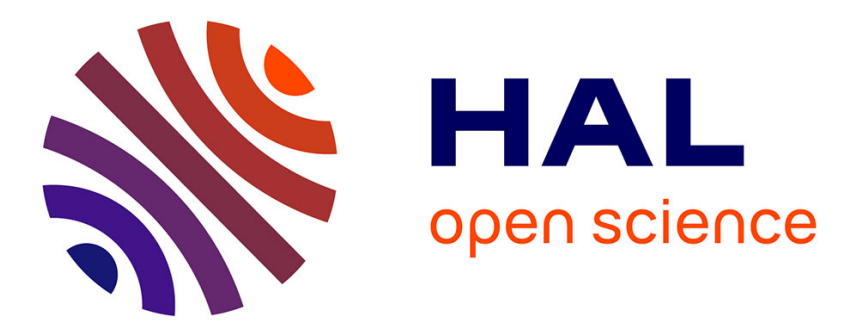

\title{
High performance of vegetables, flowers, and medicinal plants in a red-blue LED incubator for indoor plant production
}

\author{
Mohammad Sabzalian, Parisa Heydarizadeh, Morteza Zahedi, Amin \\ Boroomand, Mehran Agharokh, Mohammad Sahba, Benoît Schoefs
}

\section{To cite this version:}

Mohammad Sabzalian, Parisa Heydarizadeh, Morteza Zahedi, Amin Boroomand, Mehran Agharokh, et al.. High performance of vegetables, flowers, and medicinal plants in a red-blue LED incubator for indoor plant production. Agronomy for Sustainable Development, 2014, 34 (4), pp.879-886. 10.1007/s13593-014-0209-6 . hal-01234830

\author{
HAL Id: hal-01234830 \\ https://hal.science/hal-01234830
}

Submitted on 27 Nov 2015

HAL is a multi-disciplinary open access archive for the deposit and dissemination of scientific research documents, whether they are published or not. The documents may come from teaching and research institutions in France or abroad, or from public or private research centers.
L'archive ouverte pluridisciplinaire $\mathbf{H A L}$, est destinée au dépôt et à la diffusion de documents scientifiques de niveau recherche, publiés ou non, émanant des établissements d'enseignement et de recherche français ou étrangers, des laboratoires publics ou privés. 


\section{High performance of vegetables, flowers, and medicinal plants in a red-blue LED incubator for indoor plant production}

\author{
Mohammad R. Sabzalian • Parisa Heydarizadeh • \\ Morteza Zahedi • Amin Boroomand • Mehran Agharokh • \\ Mohammad R. Sahba • Benoît Schoefs
}

\begin{abstract}
Accepted: 19 January 2014 / Published online: 28 February 2014
(C) INRA and Springer-Verlag France 2014
\end{abstract}

\begin{abstract}
In urban agriculture, plant growth is limited by the availability of light. Light emitting diodes (LED) could provide specific quality and quantity of light overcoming existing limitations for normal plant growth. However, there have been very few investigations on the applications of LED in incubators and plant growth chambers. The devices fabricated in this study, were lighted with $100 \%$ red, $100 \%$ blue, $70 \%$ red plus $30 \%$ blue, or $100 \%$ white LED. We cultivated Mentha piperita, Mentha spicata and Mentha longifolia, lentil, basil, and four ornamentals to test the effect of various LED lights on plants productivity compared with field and greenhouse conditions. Our results show that 70/30 \% red-blue LED light increased Mentha essential oil yield up to four times along with increases in plant photosynthesis and fresh weight compared with field condition. The red-blue LED incubator also led to a better growth of lentil and basil and to higher flower buds and less days to flowering for pot flowers versus greenhouse conditions. Our findings demonstrate that LED could improve economic characteristics of plant species by probably stimulating plant metabolism.
\end{abstract}

M. R. Sabzalian $(\bowtie) \cdot$ P. Heydarizadeh $\cdot$ M. Zahedi $\cdot$ M. Agharokh Department of Agronomy and Plant Breeding, College of

Agriculture, Isfahan University of Technology, Isfahan 84156-83111, Iran

e-mail: sabzalian@cc.iut.ac.ir

\section{A. Boroomand}

Biocomputing Group, Department of Biology, University of

Bologna, Bologna 40126, Italy

M. R. Sahba

Arvin Tajhiz Espadana Company, Isfahan Science and Technology

Town, Isfahan 84156-83111, Iran

P. Heydarizadeh • B. Schoefs

MicroMar, Mer Molécules Santé, IUML - FR 3473 CNRS,

University of Le Mans, EA 2160, Faculté des Sciences et

Techniques, Le Mans, France
Keywords Essential oil · Incubator · Light emitting diodes · Mentha $\cdot$ Pot flower $\cdot$ Vegetable

\section{Introduction}

Food supply shortage due to increasing population, limited cultivated lands, serious droughts, floods, and storms as well as pest and disease outbreaks and climate changes, are forcing people to indoor and urban plant production (Yeh and Chung 2009). With demanding world of low energy input and high plant quality output, the desired planting systems should be clean; safe and eco-friendly; and simultaneously, fast, economic, and profitable. Urban culture systems and vertical farming constitute responses to these challenges to make progress in efficiently production of crop plants and vegetables.

In the past, plant culture in controlled-environments had frequent constraints particularly commercially available light sources, which could not provide a stable level of radiant energy with high photosynthetic photon flux and a spectrum close to that of sunlight. These limitations for plants growth were evident, especially for those cultured inside phytotrons and small growth chambers (incubators) (Delepoulle et al. 2008). However, the recent application of light emitting diodes (LED) in different studies suggest that they are high intensity sources of visible radiation for growing horticultural and agronomic plants under closed conditions, dominantly illuminated by blue, red, red-blue, or white LED lights (Brown et al. 1995; Yanagi and Okamoto 1997; Duong et al. 2002; Kurilcik et al. 2008). The recent decrease of both blue and red LED price together with the increase in their brightness has made LED light as an important alternative irradiation possibility, allowing better growth and production of plants and microorganisms (Table 1). For recent review, see Darko et al. (2014).

The invention of light emitting diodes (LED) could be considered as the next great innovation in lighting. The basic 
Table 1 Examples of positive effects of LED lighting on plants and microorganisms productions

\begin{tabular}{llll}
\hline Type of LED illumination & Effects & Plant/organism & Reference \\
\hline $\begin{array}{l}\text { Red-10\% Blue fluorescent light } \\
\text { Red-blue }\end{array}$ & Higher shoot dry weight, higher seed yield & Wheat & Goins et al. 1997 \\
Red-blue & Higher shoot and root fresh weight & Micropropagated strawberry plants & Nhut et al. 2000 \\
Red-blue & Larger and higher bulblet fresh and dry weight & Lilium & Lian et al. 2002 \\
& Improved flower induction, higher number of flower & Cyclamen persicum & Heo et al. 2003 \\
Blue & buds and open flowers & Thraustochytrium sp. CHN-1 & Yamaoka et al. 2004 \\
Red-blue & Higher carotenoid production & Radish and lettuce & Tamulaitis et al. 2005 \\
Blue & Higher leaf area and photosynthetic rate & Haematococcus pluvialis & Katsuda et al. 2006 \\
Red & Astaxanthin production & Spirulina platensis & Wang et al. 2007 \\
Red & Better growth & pea & Wu et al. 2007 \\
Red & Higher antioxidant activity & grape & Poudel et al. 2008 \\
Red-blue & Higher rooting percentage & Lettuce & Martineau et al. 2012 \\
Red & Economic production & Petunia, strawberry & Colquhoun et al. 2013
\end{tabular}

LED: Light Emitting Diode

LED consists of a semiconductor diode, i.e., a chip of semiconductor material doped with impurities to create a junction emitting light wavelength, depending on the band gap energy of the materials that forms the junction (Yam and Hassan 2005). They have been evolved from low-intensity signal indicators into powerful light sources (Yeh and Chung 2009). They are suitable for many applications from street lighting to lighting greenhouses and illuminating urban agricultural system, which is now a growing high-tech industry. With high efficiency, long life expectancy, small physical dimensions, low operating temperatures, and ease of control, LED lights are, therefore, expected to be developed further and become a light source with considerable potential for high-power lighting, as used where plant production could be continued all year round.

For plant culture, in addition to their monochromatic bandwidth, LED lights present several advantages including (1) maintaining constant light output over years, (2) consuming low electricity, and (3) producing low heat radiation while emitting high light intensities (Yeh and Chung 2009). The last property allows providing higher photosynthetic photon flux levels at least $500 \mu \mathrm{mol} \mathrm{m} \mathrm{m}^{-2} \mathrm{~s}^{-1}$ and higher ratio of light intensity to heat radiation compared with conventional lighting systems. This introduces LED as a promising lighting source for sustainable production in growth chambers and greenhouses.

To commercialize LED-equipped systems and to make them available to the market, they must be accompanied with sophisticated accessories to assist automatically controlling and adjusting light and probably other environmental parameters. One of these growing systems was constructed and reported for the first time by Folta et al. (2005) for plant research, which could control environmental growth factors; however, plant growth performance was not reported. In the present study, to investigate the suitability of such growth chambers, they were equipped with red-blue LED arrays (Fig. 1) in order to (1) evaluate the potential of the chambers for high quality plant production and (2) determine the effects of LED light on the growth of some medicinal and ornamental plants as compared with those grown in field or greenhouse conditions.

\section{Material and methods}

\subsection{Growth chamber construction}

The growth chamber was 1.0 width $\times 0.6$ depth $\times 1.5 \mathrm{~m}$ height surrounded by thick blocks of polyurethane foam $(3 \mathrm{~cm})$ for insulation (Fig. 1). A linear temperature gradient of $26-44^{\circ} \mathrm{C}$ could be produced by heat flow from the warm copper block to the cool copper block through the walls, floor, and lid of the chamber (each $1 \mathrm{~cm}$ thick). Temperature was measured with a digital thermometer accurate to $0.1{ }^{\circ} \mathrm{C}$ (ATE040, Arvin Tajhiz Espadana Co., Iran).

\subsection{Light control system}

Four sets of the control unit (CU) were independently designed to support 120 LED lights in four growth cabinets. LED arrays (OSRAM, Germany), emitting white (380 $760 \mathrm{~nm})$, red $(650-665 \mathrm{~nm})$, blue $(460-475 \mathrm{~nm})$, and redblue (70 \%:30\%) light were affixed to a ceramic and steel support to facilitate efficient heat transfer to the mounting substrate. All the LED lights were $1.0 \mathrm{~W}$ (0.25 A of input current) and were driven by a circuit consisted of a standard 2 A power supply delivering 110 VDC to a common bus feeding LED lights (Kaming, Taiwan) in series. Voltage to the arrays that is the illumination intensity was tuned via a selfmade potentiometer up to $500 \mu \mathrm{mol} \mathrm{m}^{-2} \mathrm{~s}^{-1}$ on each separate 
Fig. 1 Constructed light emitting diode (LED) incubator with mint plants grown under irradiation platform. This growth chamber is in size of 1.0 width $\times 0.6$ depth $\times$ $1.5 \mathrm{~m}$ height, equipped with microcontroller for setting the plant growth parameters of light, temperature and humidity to support plant superior growth
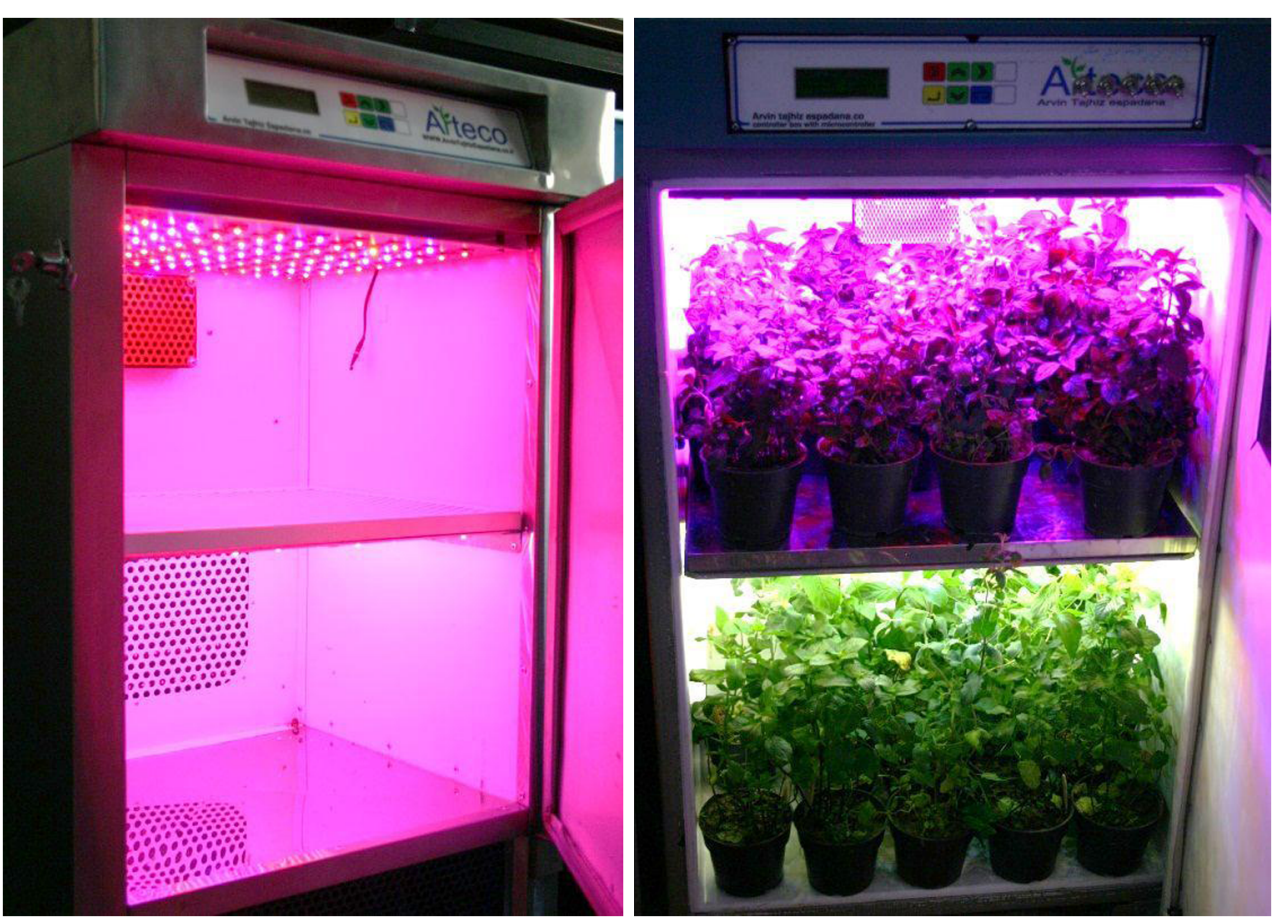

incubator at the plant leaf surface. The light intensity was also measured via a light meter (LI-250A, LI-COR Inc., USA) with a $2 \pi$ quantum sensor (LI-190, LI-COR Inc., USA) during the plants' growth. A $0.72 \mathrm{~K} \Omega(50 \mathrm{~W})$ power resistor was placed in the circuit as a current limiter. Input and output capacitors were also provided to improve transient response. This configuration was repeated for each growth chamber. The CU was outfitted with two $100 \mathrm{~mm} 12 \mathrm{~V}$ fans, one facing into and one facing out of the CU. Each individual LED sheet was also outfitted with a heat sink to ensure adequate cooling.

A microcontroller containing a logic control for setting the growth parameters was written in the assembly language of ASM51 (Arvin Tajhiz Espadana Co., Iran) and applied on each growth cabinet to adjust temperature, LED brightness, and light/dark duration $(16 / 8 \mathrm{~h})$. The cabinets were thereafter used to raise some vegetables and potted flowers, which are economically important, not previously reported to be studied under LED illumination and cultivable in indoor environments.

\subsection{Mint growth evaluation}

Five randomly selected rhizomes with the same size of three species of mint, i.e., Mentha spicata (spear mint), Mentha piperita (pepper mint), and Mentha longifolia (horse mint) were cultured in plastic pots $(10 \times 10 \mathrm{~cm})$ filled with a loam soil amended with cow manure. Mints were collected from the natural habitats of Iran (Heydarizadeh et al. 2013) and planted in the research field (Isfahan University of Technology, Isfahan, Iran, $\left.32^{\circ} 40^{\prime} \mathrm{N}, 51^{\circ} 40^{\prime} \mathrm{E}\right)$. Rhizomes were planted in pots $1-\mathrm{cm}$ deep. Pots from each mint species were placed in four LED incubators and in the field with three replications. Growth temperature was set at $25 \pm 2{ }^{\circ} \mathrm{C}$ similar to the outside average daily temperature. Pots were irrigated once a day with tap water (hardness 13, pH 7.5) and nourished with nutrient solution $(1 \mathrm{~g} / \mathrm{L})$ containing the main nutritive elements $(\mathrm{K}, \mathrm{Ca}$, $\mathrm{Mg}, \mathrm{N}, \mathrm{P}$, and S) once a week. Grown plants were photographed 60 days after planting, and net $\mathrm{CO}_{2}$ assimilation was measured by a portable photosynthesis meter (LCi ADC Instruments, UK). The aboveground part of the plants was harvested, and fresh and dry weights were determined. Dried leaves were ground using an electric grinder. The fine powder was mixed with $500-\mathrm{mL}$ distilled water and submitted to distillation for $6 \mathrm{~h}$ using a Clevenger-type 5 apparatus (British Pharmacopoeia 1980). The oil fraction was collected and weighted, and the percentage of essential oil was calculated based on dry weight unit. Plants grown in the field at the same time were treated similarly.

\subsection{Green and potted flower cultivation}

Basil (Ocimum basilicum L.) and lentil (Lens culinaris Medic) were seeds planted and seedlings of primula (Primula vulgaris Huds.), marigold (Calendula officinalis L.), treasure flower (Gazania splendens Moore), and stock plant (Matthiola incana (L.) R. Br.) were transplanted into the pots $(10 \times$ $10 \mathrm{~cm}$ ) filled with horticultural soil. Pots were placed inside a red-blue LED incubator (light: $500 \mu \mathrm{mol} \mathrm{m}^{-2} \mathrm{~s}^{-1}$; temperature: $25 \pm 2{ }^{\circ} \mathrm{C}$; humidity: $60 \pm 5 \%$ ) and in a greenhouse (as a control) in three replications. Plants were grown to full vegetative growth (for basil and lentil) or full flowering stage (for 
potted flowers), photographed and compared with plants grown under the greenhouse condition (natural light: 235$1,800 \mu \mathrm{mol} \mathrm{m} \mathrm{m}^{-2} \mathrm{~s}^{-1}$; temperature: $25 \pm 2{ }^{\circ} \mathrm{C}$; humidity: $60 \pm$ $5 \%$ ), in terms of days to full growth/flowering, the number of flowers, and plant height.

\subsection{Statistical analysis}

Plant pots at three replications were arranged in growth cabinets considered as different environments. Data were analyzed, using the Statistical Analysis System (SAS Institute Inc. 1999) program package, according to completely randomized design, and the combined analysis was performed to compare the environments. After an analysis of variance (ANOVA), significant differences among means were determined by least significant difference (LSD) test $(p<0.05)$. Principle components analysis (PCA) was also performed using SPSS (SPSS Inc. Chicago IL.V. 17).

\section{Results and discussion}

\subsection{LED light effects on plant growth}

To determine the effectiveness of light emitting diodes (LED) irradiation in plant production, economically important plants such as mint, basil, lentil, marigold, primula, treasure flower, and stock plant were grown conventionally (in the greenhouse) or in cabinets equipped with red-blue (70:30\%) LED. Generally, the plants grown under LED light were as healthy as or healthier than those grown in the greenhouse (Fig. 2). In this study, except for mint, only plant parameters mainly determining the price and marketability of the plants including days to flowering and full growth, dwarfness, and profuse flowering (Roh and Lawson 1996; Singh 2006) were recorded. As reported in Table 2, plants grown under red-blue LED irradiation were significantly smaller in size. Okamoto et al. (1997) also found that stem length in lettuce was decreased significantly with an increase in blue light. Under LED irradiation, basil and lentil reached to full growth, and buds of potted flowers were opened significantly earlier than those raised in the greenhouse. The plants grown for flowering developed significantly more floral buds per plants ( twofold) and produced plenty of flowers (Table 2).

According to our knowledge about LED lighting effects on plants, it is difficult to detail the reasons for such effects but it could be suggested that the red irradiation in the absence of far-red light is continuously stimulating phytochromes, photoreceptors controlling node elongation (Schaer et al. 1983), floral transition (Boss et al. 2004), and flowering (Runkle and Heins 2001). On the other hand, blue light inhibits cell growth, and blue light photoreceptors might regulate and change gene expression through which stem elongation is prohibited (Lin 2000; Banerjee and Batschauer 2005).

In Mentha species, plant fresh weight was significantly higher in the field in M. piperita, while in M. longifolia, redblue LED had significantly higher values than the other environments including field. For M. spicata, there was no significant difference in this regard between red-blue LED incubator and field. However, plant dry weight was significantly greater in the field in all species (Table 3). In the absence of red light, i.e., in the incubator with pure blue LED, the fresh growth was significantly lower when compared with pure red LED, except for M. longifolia, which did not show significant difference between the two lighting conditions (Table 3). In contrast, plant dry weight was not significantly different between the two pure colors incubators; however, both had lower values than that taken from red-blue LED cabinet. It has been reported that the spectral composition of red LED matches with the red absorbance area of chlorophylls $a$ and $b$ present in chloroplasts of higher plants (Schoefs 2002; Wang et al. 2007), nevertheless, it has been also reported that blue light has complementary effect. Although, red light may have higher contribution to the plant photosynthesis, our results indicate that neither pure red nor blue LED is enough to satisfy full growth of mint. Brown et al. (1995) compared pepper (Capsicum annuum L.) plants grown under red LED with similar plants grown under red LED plus blue light emitted from fluorescent lamps. Pepper biomass was reduced when plants were grown under red LED light without blue wavelengths, compared with those grown under supplemental blue lamps. Therefore, it seems that plant species could not terminate their normal growth under pure red LED light (Yorio et al. 2001).

The plants grown under white LED light displayed a significantly higher fresh weight than blue LED light (Table 3), but except for $M$. longifolia, there was no significant difference between white and red LED lights in this respect. White light is a combination of low intensities of red and blue lights and other low efficient light wavelengths, diluting the effect of red-blue light on the net photosynthesis. This may decrease the growth rate of plants illuminated by white light compared with red-blue LED lights.

Among LED lights, the maximum height belonged to the plants grown under white and red, whereas those grown under blue and red-blue were significantly shorter. However, plants grown in the field were taller than those raised under LED lights (Table 3). Light quality, especially blue and red wavelengths, controls the opening and closure of stomata (Shimazaki et al. 2007). This may change the amount of water in plant tissues, which in turn can affect plant size and height. As indicated in Table 3, the water content in plants grown in the LED cabinets fluctuated from 80.04 to $88.20 \%$, while the water content of plants raised in the field never exceeded $67.61 \%$. These data suggest that the shorter height of plants grown under LED compared with field was not related to 
Fig. 2 Comparison of growth of peppermint, basil, and marigold under red-blue light emitting diode (LED) in incubator $(\mathbf{a}-\mathbf{c})$ and inside greenhouse $(\mathbf{d}-\mathbf{f})$. The plants grown under red-blue LED were as healthy as or even better than those grown in greenhouse in terms of productivity or the number of flowers
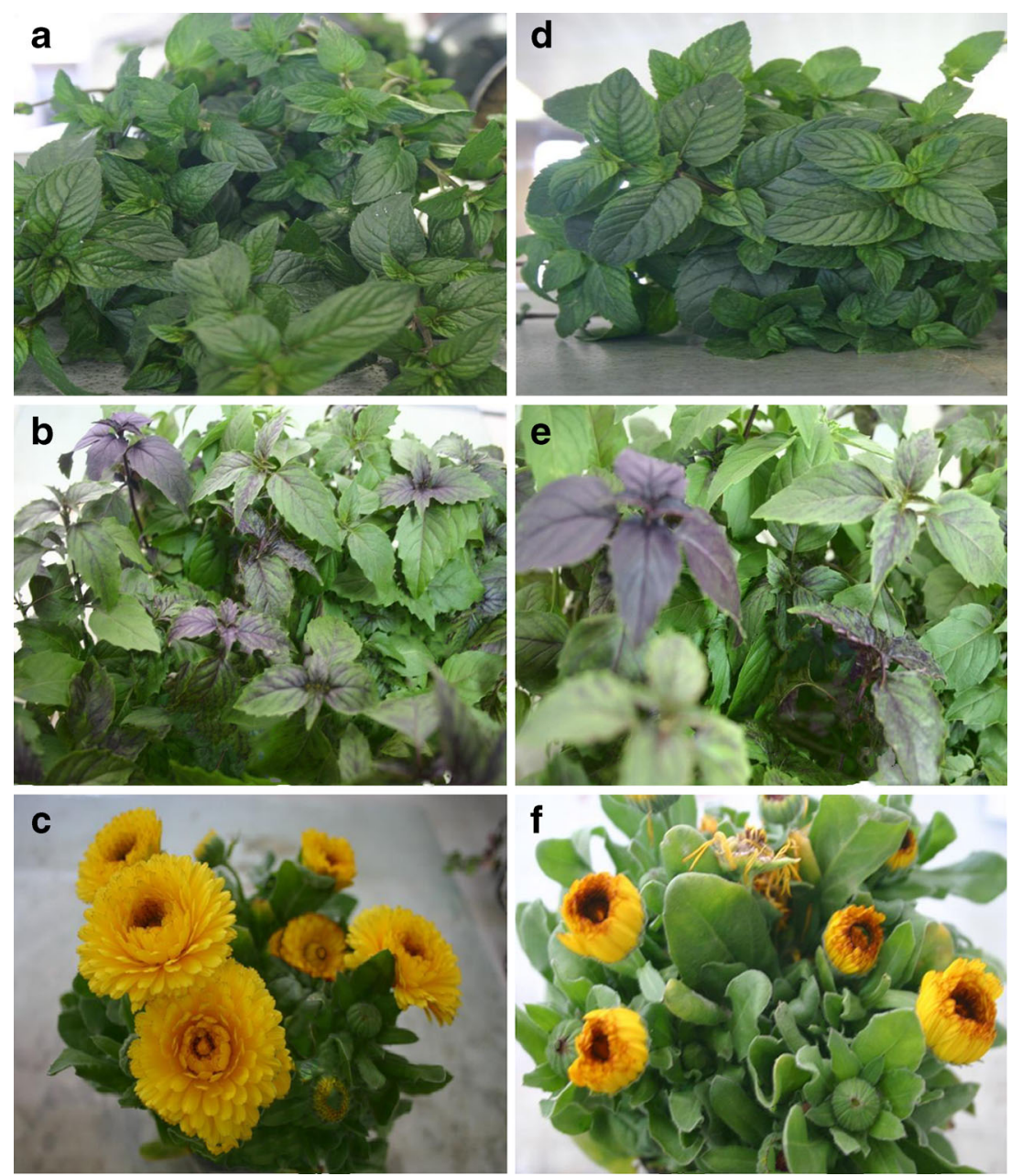

water shortage. Instead, the constant solicitation of blue photoreceptors is likely the source of reduction of plant size. The results showed that red-blue LED light improved water content and fresh weight of mint plants as good as or even better

Table 2 Mean $( \pm \mathrm{SE})$ comparison of potted plants grown under LED incubator and greenhouse in terms of days to flowering/full growth, the number of flowers and height, indicating the superiority of red-blue LED incubator

\begin{tabular}{|c|c|c|c|c|c|c|}
\hline Plant & Species & Planting source & Environment & Days to flowering/full growth & No. flowers/pot & Height $(\mathrm{cm})$ \\
\hline \multirow[t]{2}{*}{ Basil } & \multirow[t]{2}{*}{ Ocimum basilicum } & \multirow[t]{2}{*}{ Seed } & Red-blue LED incubator & $25 \pm 2.1^{\mathrm{b} *}$ & - & $23 \pm 5.6^{\mathrm{b}}$ \\
\hline & & & Greenhouse & $50 \pm 7.6^{\mathrm{a}}$ & - & $47 \pm 8.9^{\mathrm{a}}$ \\
\hline \multirow[t]{2}{*}{ Lentil } & \multirow[t]{2}{*}{ Lens culinaris } & \multirow[t]{2}{*}{ Seed } & Red-blue LED incubator & $21 \pm 1.5^{\mathrm{b}}$ & - & $19 \pm 2.5^{\mathrm{b}}$ \\
\hline & & & Greenhouse & $30 \pm 5.3^{\mathrm{a}}$ & - & $28 \pm 4.3^{\mathrm{a}}$ \\
\hline \multirow[t]{2}{*}{ Primula } & \multirow[t]{2}{*}{ Primula vulgaris } & \multirow[t]{2}{*}{ Seedling } & Red-blue LED incubator & $18 \pm 2.2^{\mathrm{b}}$ & $20 \pm 4.4^{\mathrm{a}}$ & $12 \pm 2.1^{\mathrm{b}}$ \\
\hline & & & Greenhouse & $40 \pm 6.3^{\mathrm{a}}$ & $10 \pm 3.6^{\mathrm{b}}$ & $20 \pm 5.5^{\mathrm{a}}$ \\
\hline \multirow[t]{2}{*}{ Marigold } & \multirow[t]{2}{*}{ Calendula officinalis } & \multirow[t]{2}{*}{ Seedling } & Red-blue LED incubator & $20 \pm 1.5^{\mathrm{b}}$ & $30 \pm 5.2^{\mathrm{a}}$ & $16 \pm 1.8^{\mathrm{b}}$ \\
\hline & & & Greenhouse & $50 \pm 6.7^{\mathrm{a}}$ & $15 \pm 6.3^{\mathrm{b}}$ & $28 \pm 4.8^{\mathrm{a}}$ \\
\hline \multirow[t]{2}{*}{ Treasure flower } & \multirow[t]{2}{*}{ Gazania splendens } & \multirow[t]{2}{*}{ Seedling } & Red-blue LED incubator & $37 \pm 2.6^{\mathrm{b}}$ & $15 \pm 4.5^{\mathrm{a}}$ & $18 \pm 2.3^{\mathrm{b}}$ \\
\hline & & & Greenhouse & $60 \pm 6.9^{\mathrm{a}}$ & $7 \pm 2.1^{\mathrm{b}}$ & $32 \pm 7.2^{\mathrm{a}}$ \\
\hline \multirow[t]{2}{*}{ Stock } & \multirow[t]{2}{*}{ Matthiola incana } & \multirow[t]{2}{*}{ Seedling } & Red-blue LED incubator & $28 \pm 1.1^{\mathrm{b}}$ & $45 \pm 4.5^{\mathrm{a}}$ & $21 \pm 2.3^{b}$ \\
\hline & & & Greenhouse & $58 \pm 8.5^{\mathrm{a}}$ & $22 \pm 4.8^{\mathrm{b}}$ & $36 \pm 6.4^{\mathrm{a}}$ \\
\hline
\end{tabular}

LED light emitting diode, $S E$ standard error of means

* Means followed by different letters in each column in each plant are significantly different according to LSD test $(p<0.05)$ 
Table 3 Mean comparisons of fresh and dry weight, height, water content, essential oil, and photosynthetic rate of mint plants, sampled 60 days after planting, grown in different LED cabinets and field condition

\begin{tabular}{|c|c|c|c|c|c|c|c|c|}
\hline $\begin{array}{l}\text { Incubator/ } \\
\text { environment }\end{array}$ & Mentha species & $\begin{array}{l}\text { Photosynthesis } \\
\left(\mu \mathrm{Mol} \mathrm{CO} \mathrm{CO}_{2}\right. \\
\left.\mathrm{m}^{-2} \mathrm{~s}^{-1}\right)\end{array}$ & $\begin{array}{l}\text { Height } \\
(\mathrm{cm})\end{array}$ & $\begin{array}{l}\text { Fresh weight } \\
\text { (g/plant) }\end{array}$ & $\begin{array}{l}\text { Dry weight } \\
\text { (g/plant) }\end{array}$ & $\begin{array}{l}\text { Dry weight (g) } \\
\mathrm{cm}^{-1}\end{array}$ & $\begin{array}{l}\text { Water content } \\
\text { (\% of fresh } \\
\text { weight) }\end{array}$ & $\begin{array}{l}\text { Essential oil } \\
\text { content } \\
\text { (\% of dry } \\
\text { weight })\end{array}$ \\
\hline \multirow[t]{3}{*}{ Red LED } & Mentha piperita & 14.28 & 20.8 & 16.73 & 2.24 & 0.11 & 86.61 & 7.00 \\
\hline & Mentha spicata & 8.74 & 24.1 & 18.72 & 2.21 & 0.09 & 88.20 & 4.34 \\
\hline & Mentha longifolia & 5.62 & 28.1 & 13.37 & 1.89 & 0.07 & 85.84 & 4.37 \\
\hline \multirow[t]{3}{*}{ Blue LED } & Mentha piperita & 8.83 & 12.1 & 6.39 & 1.27 & 0.10 & 80.04 & 3.11 \\
\hline & Mentha spicata & 4.96 & 12.7 & 6.24 & 1.24 & 0.10 & 80.10 & 5.03 \\
\hline & Mentha longifolia & 3.21 & 16.2 & 10.27 & 1.95 & 0.12 & 81.02 & 3.19 \\
\hline \multirow[t]{3}{*}{ Red-blue LED } & Mentha piperita & 20.70 & 13.2 & 27.36 & 4.45 & 0.34 & 83.71 & 5.12 \\
\hline & Mentha spicata & 16.17 & 14.5 & 25.89 & 4.17 & 0.29 & 83.89 & 2.60 \\
\hline & Mentha longifolia & 6.48 & 19.4 & 36.99 & 6.10 & 0.31 & 83.50 & 4.86 \\
\hline \multirow[t]{3}{*}{ White LED } & Mentha piperita & 15.27 & 23.5 & 16.03 & 2.67 & 0.11 & 83.33 & 2.34 \\
\hline & Mentha spicata & 10.81 & 26.7 & 17.85 & 3.30 & 0.12 & 81.48 & 2.58 \\
\hline & Mentha longifolia & 4.52 & 31.9 & 17.70 & 2.70 & 0.08 & 84.75 & 3.53 \\
\hline \multirow[t]{3}{*}{ Field } & Mentha piperita & 18.89 & 52.1 & 32.90 & 11.23 & 0.22 & 65.87 & 1.40 \\
\hline & Mentha spicata & 14.00 & 52.1 & 23.06 & 7.47 & 0.14 & 67.61 & 0.66 \\
\hline & Mentha longifolia & 4.61 & 59.7 & 11.60 & 8.08 & 0.14 & 30.34 & 3.33 \\
\hline $\operatorname{LSD}^{*}(0.05)$ & - & 2.08 & 5.65 & 3.31 & 1.06 & 0.03 & 5.31 & 0.59 \\
\hline
\end{tabular}

LSD least significant difference, $L E D$ light emitting diode

*Means having difference lower than LSD are not significantly different $(P<0.05)$.

than field condition. It is worth mentioning that high fresh weight and water content are the two important characteristics of mint for fresh uses.

Since the total biomass production of plants could be influenced by plant size as a function of light quality, the dry weight per each height unit was used as a proxy of yield index after 2 months. The lowest values of $0.08-0.12 \mathrm{~g}$ dry weight $\mathrm{cm}^{-1}$ were found under red and white LED irradiation and the highest values of $0.29-0.34 \mathrm{~g}$ dry weight $\mathrm{cm}^{-1}$ were observed under red-blue LED. The values obtained for the plants grown in the field were intermediate (Table 3). The spectral composition of blue (460-475 nm) and red (650-665 nm) LED fits

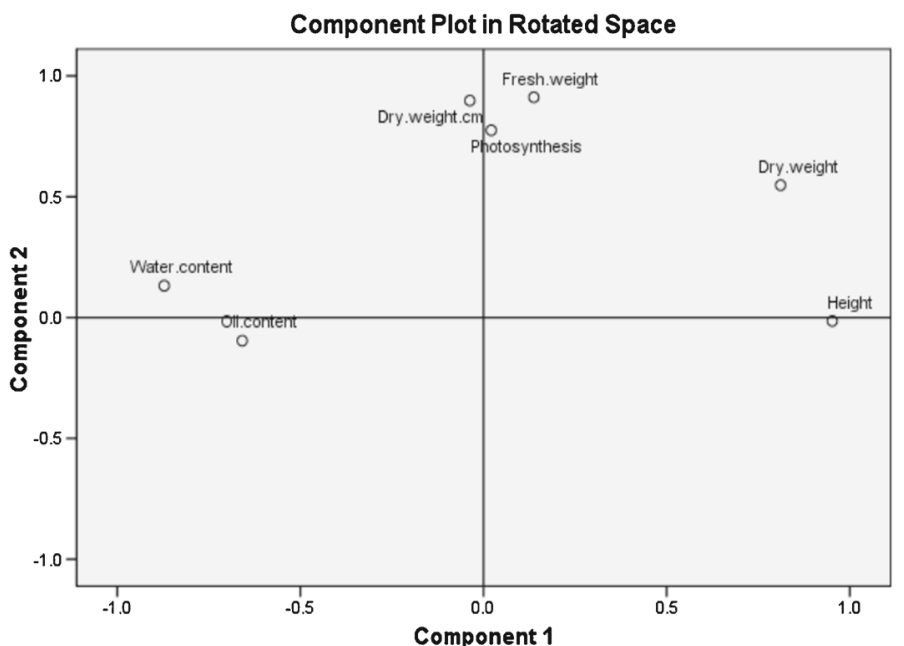

Fig. 3 The collinearity among mint characteristics using principle components analysis. The plot of principle components shows high trend between the photosynthetic activity with fresh weight and dry weight per

\begin{tabular}{|c|c|c|}
\hline & \multicolumn{2}{|c|}{ Rotated Components } \\
\hline Characteristic & 1 & 2 \\
\hline Photosynthesis & .021 & .775 \\
\hline Height & .952 & -.014 \\
\hline Fresh Weight & .137 & .912 \\
\hline Dry Weight & .811 & .548 \\
\hline Dry Weight $\mathrm{cm}^{-1}$ & -.038 & .898 \\
\hline Water Content & -.872 & .132 \\
\hline Oil Content & -.659 & -.096 \\
\hline \% of variance & 45.29 & 31.05 \\
\hline
\end{tabular}

plant size indicating that higher photosynthesis under LED is correlated with increase in fresh and specific dry weight 
well to the light absorption spectrum of carotenoids and chlorophyll pigments (Schoefs 2002). Therefore, it was determined whether the increase in dry weight per plant size unit is due to an increase in the photosynthetic activity of the plants. To test this, the $\mathrm{CO}_{2}$ fixation was first measured and then principle components analysis (PCA) was performed in order to understand the relation between photosynthesis rate and the other variables (Fig. 3). Despite the fact that the values of photosynthesis greatly varied with species and light quality, the highest values were always found in M. piperita and the lowest in M. longifolia (Table 3). The plot of depicting variables based on the two first principle components shows no particular trend between the photosynthetic activity and dry weight, suggesting that the strategy in utilization of fixed $\mathrm{CO}_{2}$ is different, depending on the light source. However, there was high collinearity between dry weight per plant size and fresh weight with photosynthesis indicating that higher photosynthesis under LED is correlated with increase in fresh and specific dry weight.

\subsection{LED light effects on mint essential oil}

It has been well-established that light quality constitutes signals that can trigger metabolic modifications (Liu et al. 2004). To test this with LED light, three mint species grown in growth cabinets each equipped with red, blue, red-blue, or white LED were analyzed for their essential oil content. Our results demonstrated that mint plants of all three species grown under red or red-blue LED light accumulated dramatically higher essential oil content compared with those grown in the field. The maximum increase in oil content was fourfold higher in M. piperita grown under red LED light compared with the field. Under blue or white LED light, significant increases in essential oil content were also observed compared with the field except for M. longifolia (Table 3).

There is limited information on stimulation of the essential oil accumulation in plants with medicinal properties under LED lights. It seems that red LED may affect the metabolic pathways, leading to an increase in essential oil content. The positive effect of LED light on metabolic pathways has not been well-documented; however, there are possible hypotheses about the role of LED light on increasing biosynthesis of some metabolites. Liu et al. (2004) hypothesized that red LED light may repress the expression of negative regulator genes of pigmentation like LeCOP1-LIKE, resulting in plants with dark green leaves and elevated carotenoid levels. It has been also postulated that LED light could affect secretion or stability of or sensitivity to phytohormones, consistent with the improvement in morphogenesis and productivity of the plant in response to LED lighting (Tamulaitis et al. 2005). However, how these changes take place and affect essential oil accumulation is not yet known and warrant further investigations because of their high positive impact on economic extraction and value of essential oil from plants grown under LED lighting.

\section{Conclusion}

The development of human population mostly relies on plant species for nutrition, health, and other human activities. Due to environmental constraints and limited cultivated lands, it is critical to develop indoor systems, allowing significantly higher or at least similar production of yield than outdoor environments. To fulfill this demand, a LED incubator was constructed and evaluated in this study. It offers LED lighting regimes supporting complete plant growth and development. The device provided conditions for a faster growth of mint, lentil and basil, and some ornamental plants in our experiments. LED lights were used because they do not include the drawbacks of traditional nondurable lamp systems. The results of this work demonstrated that the studied vegetables and potted flowers took benefits from LED lighting such as dwarfness and increased essential oil production. Among the LED light qualities, most of the beneficial effects were best obtained when red-blue illumination was applied. This conclusion agreed with those attained on the growth and morphogenesis of lettuce and radish in the previous research. LED lighting may provide a novel tool and a new challenge for agricultural research and production alongside its influence on plant morphology and composition. LED lights could be easily integrated into incubators having control systems in which complex lighting programs are facilitated, including selected spectral composition over a growth period or the whole plant developmental stage for improving quality and economic yield of plant species.

Acknowledgments The corresponding author would like to thank the Iranian National Elites Foundation and Isfahan University of Technology for the financial support of this research. BS also thanks the University of Le Mans for support. We would also like to express our appreciation to Mr. Ehsan Ataii for the assistance in conducting experiments and Prof. Aghafakhr Mirlohi for the critical review of the preliminary draft of this manuscript.

\section{References}

Banerjee R, Batschauer A (2005) Plant blue-light receptors. Planta 20: 498-502. doi:10.1007/s00425- 004-1418-Z

Boss PK, Bastow RM, Mylne JS, Dean C (2004) Multiple pathways in the decision to flower: enabling, promoting, and resetting. Plant Cell 16:S18-S31. doi: $10.1105 / \mathrm{tpc} .015958$

British Pharmacopoeia, (1980) H. M. S. Office. 2, London, pp 109-110

Brown CS, Schuerger AC, Sager JC (1995) Growth and photomorphogenesis of pepper plants under red light-emitting diodes with supplemental blue or far-red lighting. J Am Soc Hortic Sci 120:808-813 
Colquhoun TA, Schwieterman ML, Gilbert JL, Jaworski EA, Langer KM, Jones CR, Rushing GV, Hunter TM, Olmstead J, Clark D, Folta KM (2013) Light modulation of volatile organic compounds from petunia flowers and select fruits. Postharvest Biol Technol 86: 37-44. doi:10.1016/j.postharvbio.2013.06.013

Darko E, Heydarizadeh P, Schoefs B, Sabzalian MR (2014) Photosynthesis under artificial light: the shift in primary and secondary metabolism. Phil Trans R Soc B 20130243. doi:10.1098/ rstb.2013.0243

Delepoulle S, Renaud C, Chelle M (2008) Improving light position in a growth chamber through the use of a genetic algorithm. In: Plemenos D, Miaoulis G (eds), Artificial Intelligence Techniques for Computer Graphics Studies in Computational Intelligence, Springer, Berlin, Heidelberg, pp. 67-82

Duong TN, Hong LTA, Watanabe H, Goi M, Tanaka M (2002) Growth of banana plantlets cultured in vitro under red and blue light-emitting diode (LED) irradiation source. Acta Horticult 575:117-124

Folta KM, Koss LL, McMorrow R, Kim H-H, Kenitz JD, Wheeler R, Sager JC (2005) Design and fabrication of adjustable red-green-blue LED light arrays for plant research. BMC Plant Biol. 5:17. doi: 10. 1186/1471-2229-5-17

Goins GD, Yorio NC, Sanwo MM, Brown CS (1997) Photomorphogenesis, photosynthesis, and seed yield of wheat plants grown under red lightemitting diodes (LEDs) with and without supplemental blue lighting. J Exp Bot 48:1407-1413

Heo JW, Lee CW, Murthy HN, Paek KY (2003) Influence of light quality and photoperiod on flowering of Cyclamen persicum Mill. cv. 'Dixie White'. Plant Growth Regul 40:7-10. doi:10.1023/ a:1023096909497

Heydarizadeh P, Zahedi M, Sabzalian MR, Ataii E (2013) Mycorrhizal infection, essential oil content and morpho-phenological characteristics variability in three mint species. Sci Hortic 153:136-142. doi: 10.1016/j.scienta.2013.01.014

Katsuda T, Shimahara K, Shiraishi H, Yamagami K, Ranjbar R, Katoh S (2006) Effect of flashing light from blue light emitting diodes on cell growth and astaxanthin production of Haematococcus pluvialis. J Biosci Bioeng 102:442-446. doi:10.1263/jbb.102.442

Kurilcik A, Miklusyte-Canova R, Dapkuniene S, Zilinskaite S, Kurilcik G, Tamulaitis G, Duchovskisand P, Zukauskas A (2008) In vitro culture of Chrysanthemum plantlets using light-emitting diodes. Cent Eur J Biol 2:161-167. doi:10.2478/s11535-008-0006-9

Lian M-L, Murthy HN, Paek K-Y (2002) Effects of light emitting diodes (LEDs) on the in vitro induction and growth of bulblets of Lilium oriental hybrid 'Pesaro'. Sci Hortic 94:365-370. doi:10.1016/ S0304-4238(01)00385-5

Lin C (2000) Plant blue-light receptors. Trends Plant Sci 5:337-342

Liu Y, Roof S, Ye Z, Barry C, van Tuinen A, Vrebalov J (2004) Manipulation of light signal transduction as a means of modifying fruit nutritional quality in tomato. PNAS 101:9897-9902. doi:10. 1073/pnas.0400935101

Martineau V, Lefsrud M, Tahera Nazanin M, Kopsell DA (2012) Comparison of light-emitting diode and high-pressure sodium light treatments for hydroponics growth of Boston lettuce. Hortscience 47:477-482

Nhut DT, Takamura NT, Watanabe H, Tanaka M (2000) Light emitting diodes (LEDs) as a radiation source for micropropagation of strawberry. In: Kubota C, Chun C (eds.), Transplant production in the 21st century, Kluwer Academic Publishers, Dordrecht, The Netherlands, pp 114-118

Okamoto K, Yanagi T, Kondo S (1997) Growth and morphogenesis of lettuce seedlings raised under different combinations of red and blue light. Acta Horticult 435:149-157

Poudel PR, Kataoka I, Mochioka R (2008) Effect of red- and blue-lightemitting diodes on growth and morphogenesis of grapes. Plant Cell Tissue Organ Cult 92:147-153. doi:10.1007/s11240-007-9317-1

Roh MS, Lawson RH (1996) Requirements for new floral crops-perspectives for the United States of America. Acta Horticult 454:29-38

Runkle ES, Heins RD (2001) Specific functions of red, far red, and blue light in flowering and stem extension of long-day plants. J Am Soc Hortic Sci 126:275-282

SAS Institute, Inc (1999) SAS/STAT User's Guide. SAS Institute, Inc, Cary

Schaer JA, Mandoli DF, Briggs WR (1983) Phytochrome-mediated cellular photomorphogenesis. Plant Physiol 72:706-712

Schoefs B (2002) Chlorophyll and carotenoid analysis in food products. Properties of the pigments and methods of analysis. Trends Food Sci Technol 13:361-371. doi:10.1016/S0924- 2244(02) 00182-6

Shimazaki K, Doi M, Assmann SM, Kinoshita T (2007) Light regulation of stomatal movement. Annu Rev Plant Biol 58:219-247. doi:10. 1146/annurev.arplant.57.032905.105434

Singh AK (2006) Flower crops: cultivation and management. New India Publishing Agency, Pitampuram

Tamulaitis G, Duchovskis P, Bliznikas Z, Breive K, Ulinskaite R, Brazaityte A, Novickovas A, Zukauskas A (2005) Highpower light-emitting diode based facility for plant cultivation. J Phys D Appl Phys 38:3182-3187. doi:10.1088/0022-3727/ $38 / 17 / \mathrm{S} 20$

Wang C-Y, Fub C-C, Liu Y-C (2007) Effects of using light-emitting diodes on the cultivation of Spirulina platensis. Biochem Eng J 37:21-25. doi:10.1016/j.bej.2007.03.004

Wu M-C, Hou C-Y, Jiang C-M, Wang Y-T, Wang C-Y, Chen H-H, Chang H-M (2007) Novel approach of LED light radiation improves the antioxidant activity of pea seedlings. Food Chem 101:1753-1758. doi:10.1016/j.foodchem.2006.02.010

Yam FK, Hassan Z (2005) Innovative advances in LED technology. Microelectron J 36:129-137. doi:10.1016/j.mejo.2004.11.008

Yamaoka Y, Carmona ML, Oota S (2004) Growth and carotenoid production of Thraustochytrium sp. CHN-1 cultured under super-bright red and blue light-emitting diodes. Biosci Biotechnol Biochem 68: 1594-1597

Yanagi T, Okamoto K (1997) Utilization of super-bright light emitting diodes as an artificial light source for plant growth. Acta Horticult 418:223-228

Yeh N, Chung J-P (2009) High-brightness LEDs-energy efficient lighting sources and their potential in indoor plant cultivation. Renew Sustain Energ Rev 13:2175-2180. doi:10.1016/j. mejo.2004.11.008

Yorio NC, Goins GD, Kagie HR, Wheeler RM, Sager JC (2001) Improving spinach, radish, and lettuce growth under red lightemitting diodes (LEDs) with blue light supplementation. Hortscience 36:380-383 